\title{
Capturing the light
}

\author{
P. P. Strona \\ Turin, Italy
}

\begin{abstract}
The aim of this paper is to show how beautiful, artistic images can be created by capturing the light around us. Light allows us to see the reality of the world and can make even very ordinary things wonderful. After some thought about photography from the artistic point of view, daylight, moonlight and artificial lights are considered. Then the interaction of light with water and glass is examined, particularly focussing on its ability to generate surreal and oneiric views. Finally some examples of ways of capturing the light are given.

Keywords: photography, art, daylight, moonlight, surreal views, images in water, images in glass, frames.
\end{abstract}

\section{Introduction}

Since pre-historic times man has felt the need to represent anything he saw in some way, both as a way of remembering and depicting its beauty and as a means of communication. First in drawings, then in painting and frescoes, in which the light constitutes the even more conscious basis and the structure of the work. Rubens in Holland, Caravaggio in Italy, Turner in England are just examples of the great painters who have made light the essence of their oeuvre.

For little more than a century technology has enabled us to represent everything around us on paper with the help of a camera which can catch light and fix images on paper. Thus a new path of creativity was traced and photography became another way of recording and representing the world, alongside drawing and painting, using different techniques but with analogous content and purpose.

Taking photographs means first and foremost looking around, observing, seeing what people often or almost always fail to see and fixing it on some surface, so as to be able to communicate it to the others. Hence photography becomes a language used between men and women capable of expressing 
concepts and transmitting beauty in efficacious and specific ways, alternative or complementary to spoken languages.

Figure 1 is an example of this. This image shows part of a skyscraper lit up by the sun: every window reflects the same image of a detail of the skyscraper opposite but distorts it in a different way, thus expressing concepts which would take many words to express in verbal language. In short, each of us filters the reality in which he is immersed in his own way, everything is subjective. Perhaps the "truth" lies in the sunlight, but nothing can be made out there anymore, and so man is not allowed to reach it, everyone is prisoner of his own individual truth. Pirandello wrote many works to get these concepts into focus.

Figure 2 represents another example of the expression and communication of concepts. There are two different types of geometrical pattern in this image, the one, Euclidean and sail-like, and the other, fractal and clouds-like: Euclid and Mandelbrot, separated by about 2000 years, in the same image.

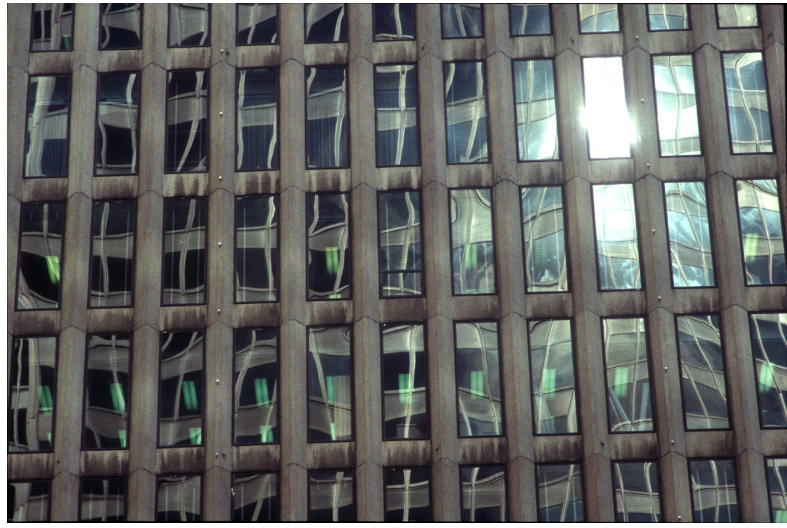

Figure 1: "Pirandello".

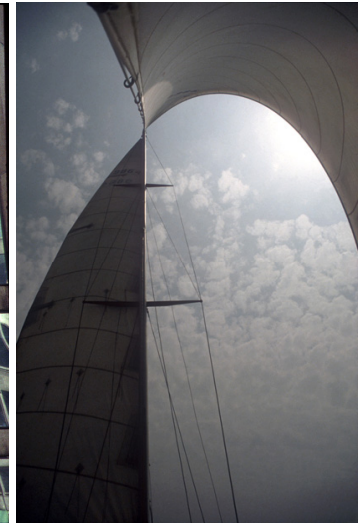

Figure 2: $\quad$ Sailing.

However as we look at these photographs we also notice that the essential "element" that gives form and life to the images is light. Light creates the world we perceive around us and, according to how he captures it, the photographer can make something beautiful, a work of art, or a commonplace, unmeaningful image. Playing with light, choosing the best moment to take the shot, choosing the frame that enhances the subject, bringing out its hidden geometric structures, exploiting the contrasts between light and dark areas: in photography it all depends on learning to capture light.

So let us begin with the main sources of light and then observe the images that the light forms, particularly those that it creates by interacting with elements that are interesting and stimulating for the photographer, such as water and glass.

\section{Sources of light}

The sun and the stars are the main sources of light which shines on our world. So the wish to represent them in images arises spontaneously. Almost everyone 
must have tried to take a photograph of the sun, especially at dawn or sunset, when it is low on the horizon and easier to look at. Its light creates intense, romantic effects, the play of oblique light and shadow gives depth and fullness to the scene framed. But the photographer can also play at picking out strange, unusual situations like the one in figure 3, where the sun is captured at dawn, just above the chimney of a house, composing something like an enormous "lampshade".

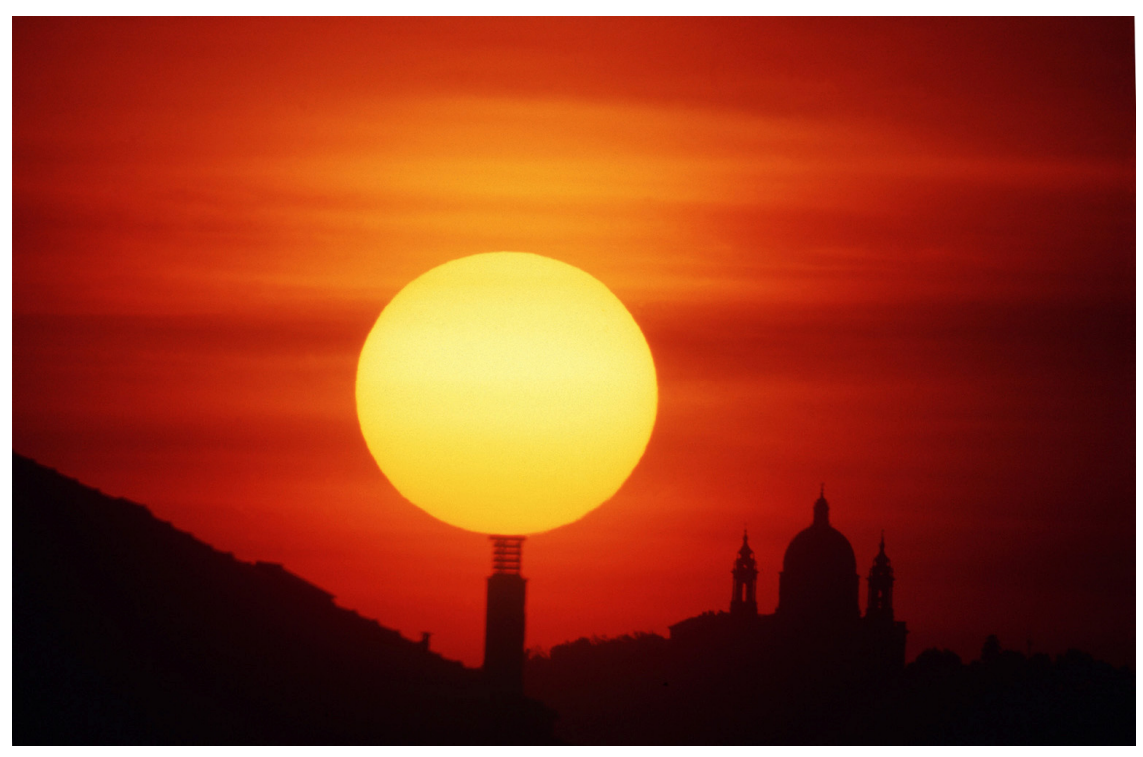

Figure 3: The "lampshade", Turin, Superga, Italy.

The stars, too, can create fascinating images. As he attempts to represent them, the photographer can even capture things not visible to the human eye, which yet give a sense of the magic of the night sky. By directing the camera northwards and leaving the shutter open for a long time, you obtain an image with circles described by the stars as a result of the earth's rotation. They are circles of various colours concentric with the Northern star. In the case of figure 4 the time of exposure was almost one hour.

By choosing a suitable exposure time, after trial and error, the landscape framed can also be lit up while leaving the impression of a night sky. The exposure time in figure 5 , as can be seen from the length of the arcs, was about three hours.

The moon sends us a reflected light, but perhaps precisely because of this it is very fascinating and mysterious (Fig. 6). The exposure time is much shorter and the circles of the stars become small segments. 


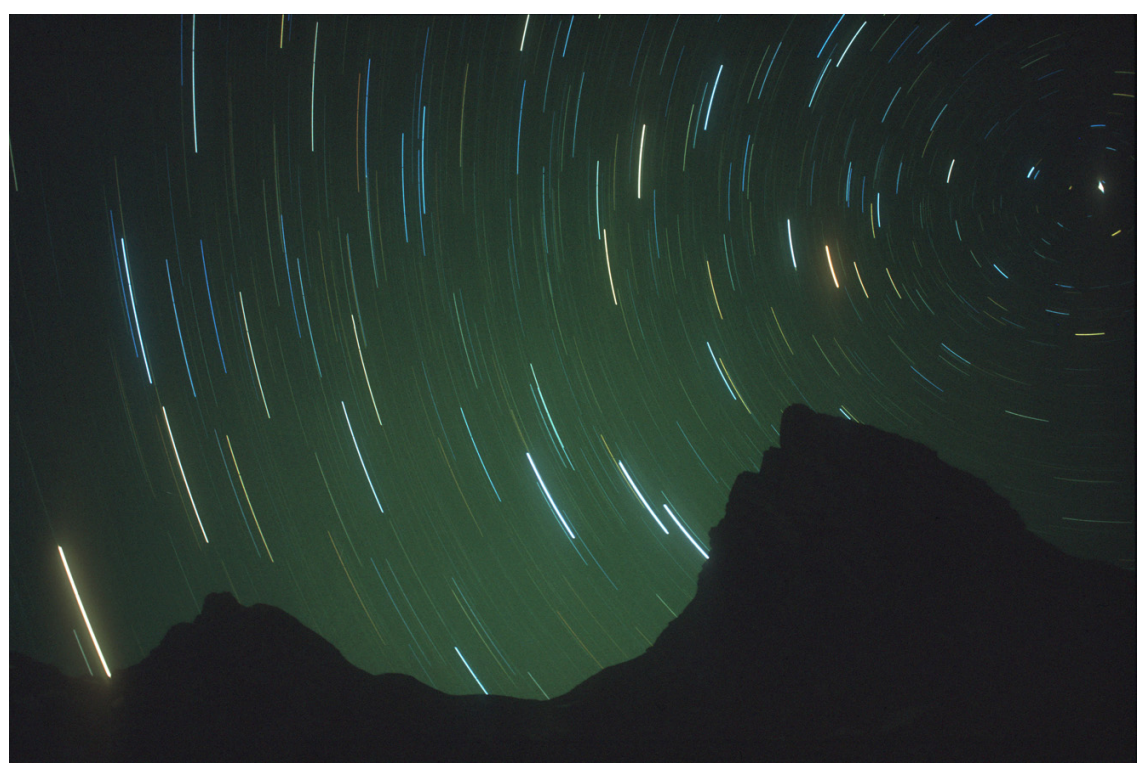

Figure 4: The sky by night, Gran San Bernardo pass, from Italy to Switzerland.

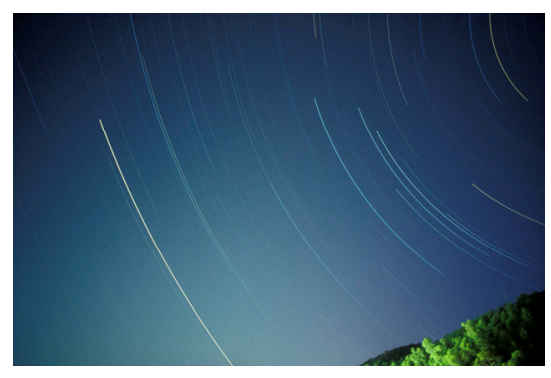

Figure 5: The sky by night.

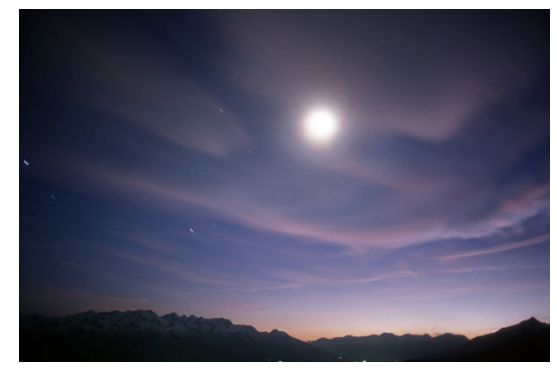

Figure 6: Moonlight.

\section{Nocturnal impressions}

There are some especially interesting kinds of light that only last for a moment; in those few minutes, when the day is done but the night has not yet taken over, the artificial lighting has already been turned on but the natural light persists, though faintly. At such moments, the photographer can create especially evocative images (Fig. 7), with a different atmosphere from those taken at dead of night (Fig. 8). 


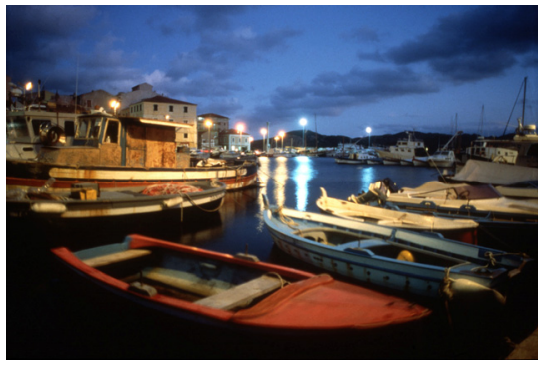

Figure 7: La Maddalena, Italy.

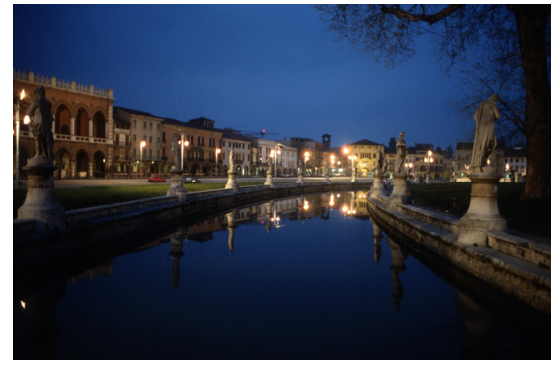

Figure 8: $\quad$ Padua, Italy.

\section{Light and water}

Light, interacting with water, sometimes creates dream-like surreal images, generally in puddles, which produce very interesting and complex effects. The photographer can play not only with the images reflected in the water, but, for example, with the ground under the water, objects that may be floating on it, and with its fanciful geometric shapes. Therefore the photographer has to take into consideration light, reflected images, transparencies and geometry all at the same time.

Sometime puddles can break up reflections creating geometrical harmonies and fascinating atmospheres (Figs. 9, 10). In other cases almost surreal situations can be caught by including non-reflected zones in the frame (Fig. 11).

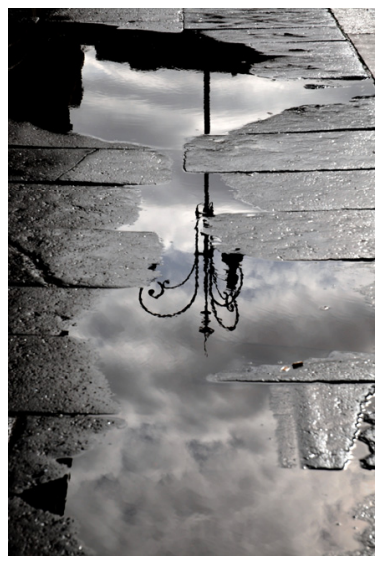

Figure 9: Rome, Italy

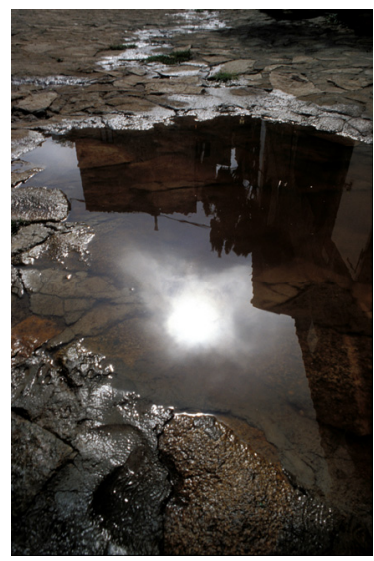

Figure 10: Giglio, Italy

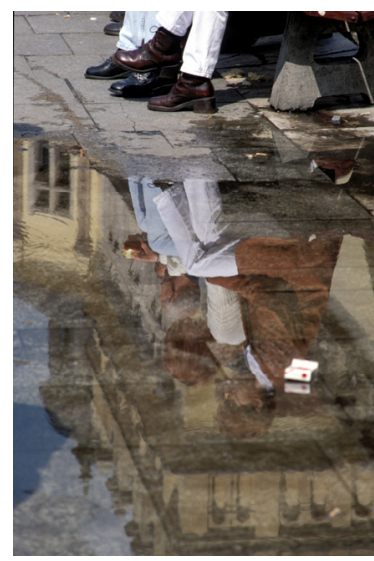

Figure 11: Krakow, Poland

Often it is interesting to turn images upside down [1], obtaining new unusual fascinating effects (Fig. 12). 

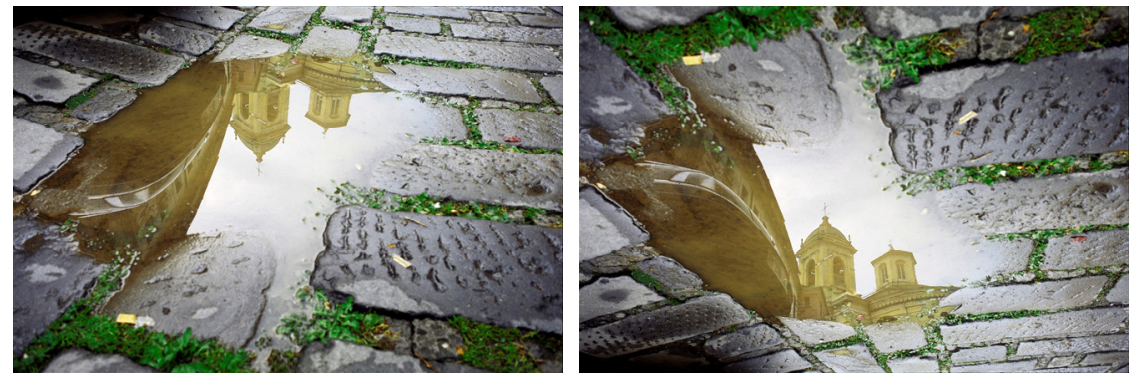

Figure 12: Pieve di Teco, Italy.

\section{$5 \quad$ Light and glass}

Through glass perhaps more than through water light can create wonderful, incredible but real images. Light passes through the glass, which reflects it and breaks it up into two superimposed images which the observer does not generally look at together. Yet if we try to observe the resulting image, in the streets of a town for example, where there is glass almost everywhere, we get a new townscape and discover images that generally escape most people and which can be caught directly and easily by the camera, without any further elaboration.

Anyone strolling along the streets of a town or a village can watch and enjoy the lights, the shapes and the colours forming wonderful images. Although at

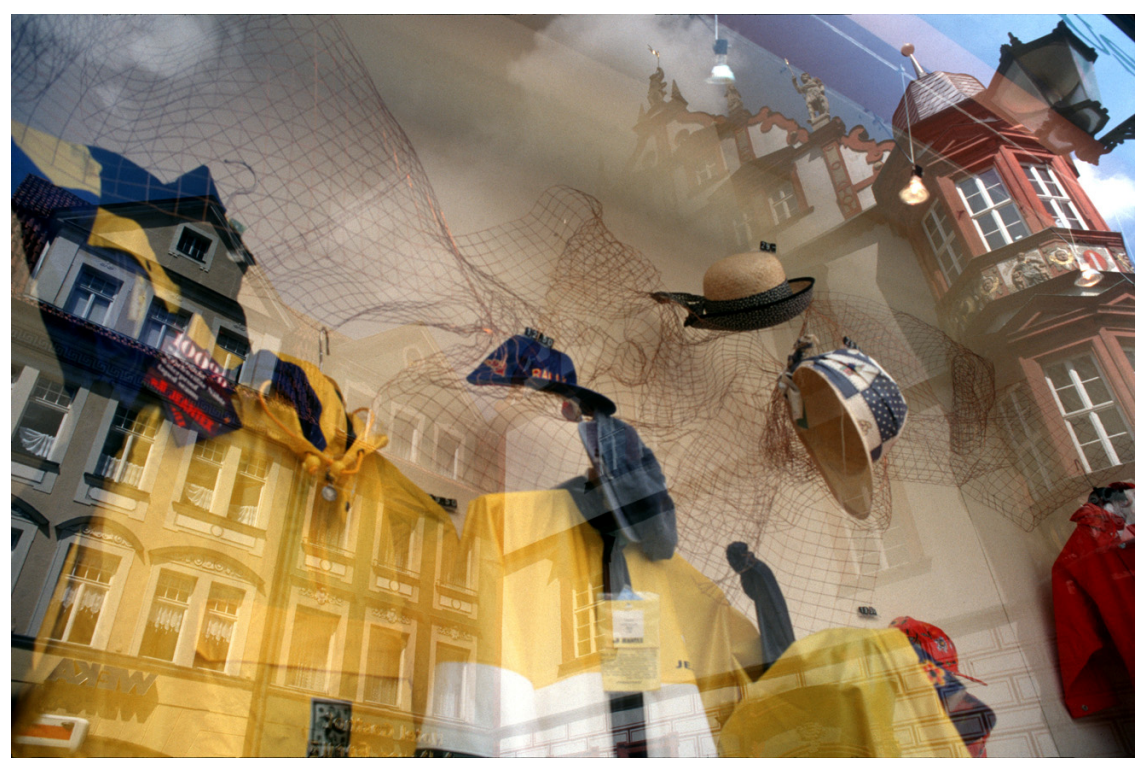

Figure 13: Coburg, Germany. 
first sight they may appear fictitious and obtained through complex techniques, these surreal and sometimes dream-like compositions, almost an abstract play on shapes and colours, are in fact simple images of reality captured through the lens of a camera, single shots taken while observing, maybe with a touch of irony, the urban landscape surrounding us. As we look at these images we realize that reality can be more fanciful and unpredictable than any type of imagination.

Let us consider some examples:

Reflected houses and objects on show in the shop-window, framed very accurately, give a single harmonious image both in form and shade of colour (Fig. 13).

Sometimes you get funny situations, for instance [2] suitcases on the roofs of buildings (Fig. 14) or a ghost-tram which appears and disappears in a split second (Fig. 15), or a bedroom where surely privacy is at a minimum (Fig. 16). Whereas in the picture in figure 17 , by choosing carefully the point from which the frame is taken, the gradual passage from the book structure to the architectural building structure can be brought out.

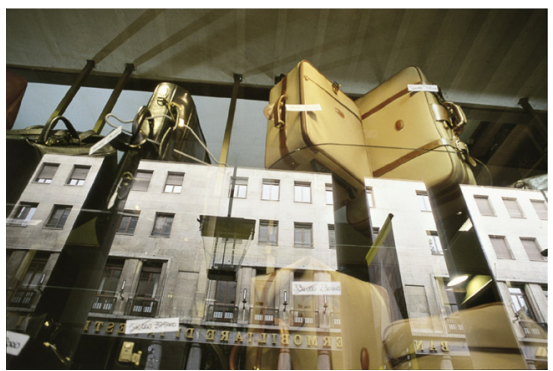

Figure 14: Turin, Italy.

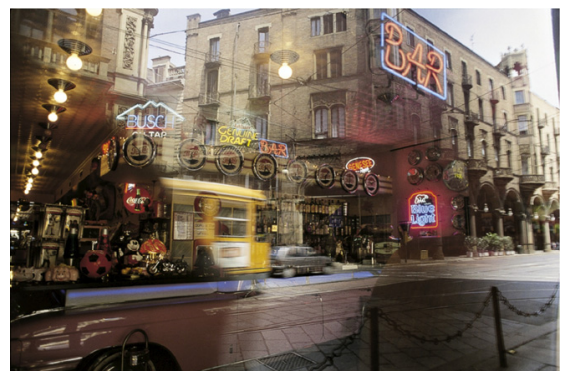

Figure 15: Turin, Italy.

Finally, by using a fish-eye lens, the whole shop-window can be included in the image, so that the overlapping vision seems like that of a TV set (Fig. 18). With a touch of irony even a "meta-TV" could be found (Fig. 19).

\section{Some examples of how to catch light and water}

So far we have considered light as the means of catching images and seen how the photographer can interpret reality artistically, by catching features and situations and creating images which show what people do not usually notice or observe.

There is also another level, perhaps a little more technical, at which light can be captured. At this level artistic images can be created by playing on details, which ultimately constitute the experience the photographer has gathered over the years. 
244 Lighting in Engineering, Architecture and the Environment

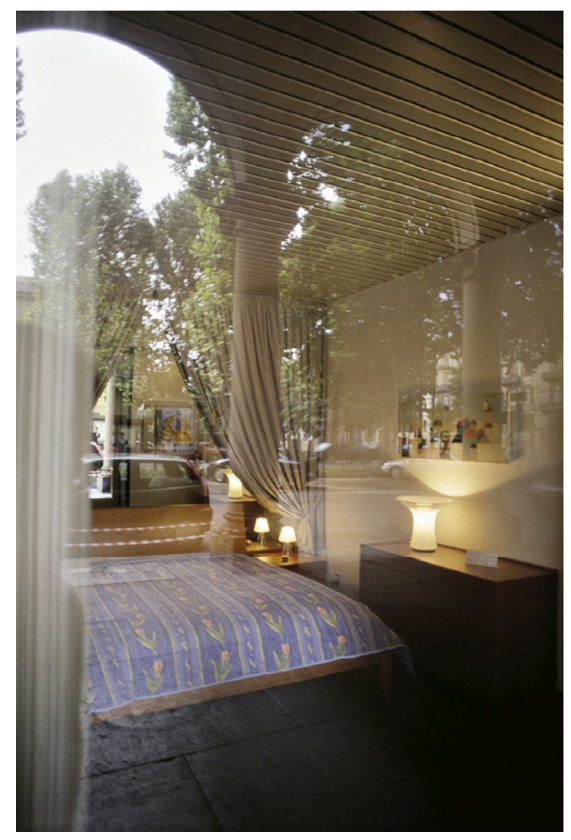

Figure 16: Turin, Italy.

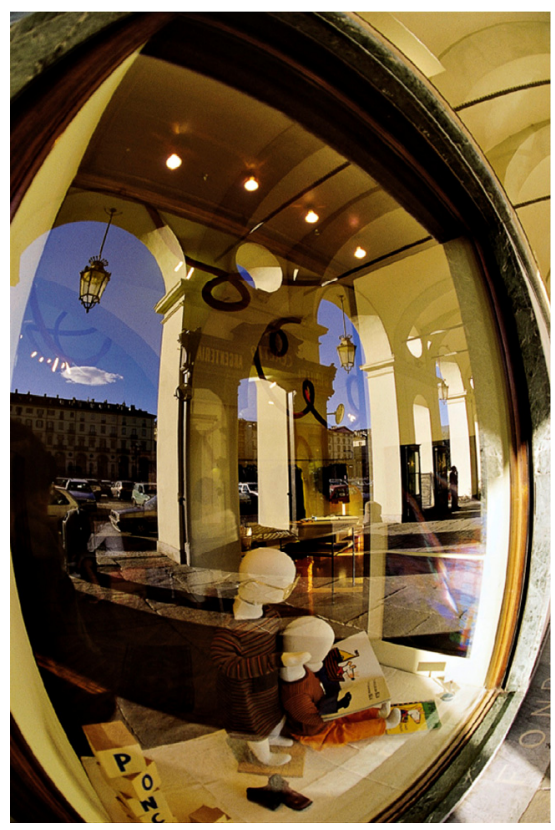

Figure 18: Turin, Italy.

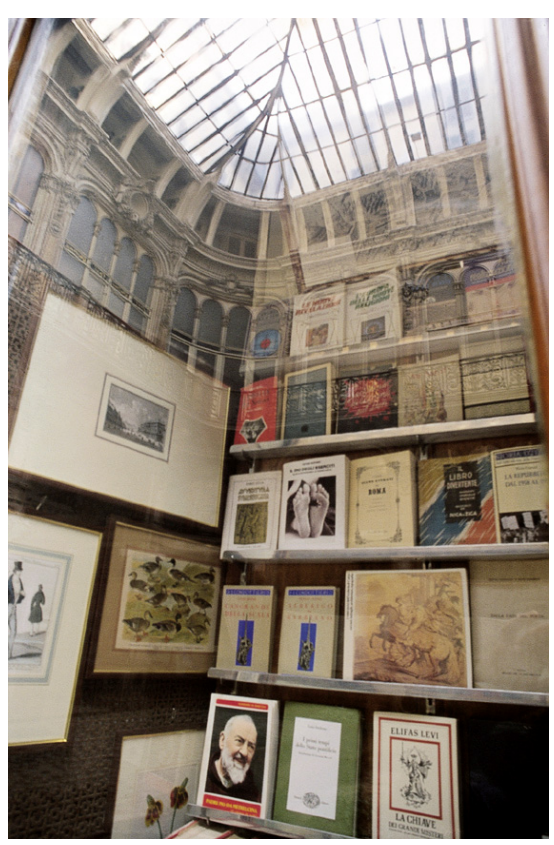

Figure 17: Turin, Italy.

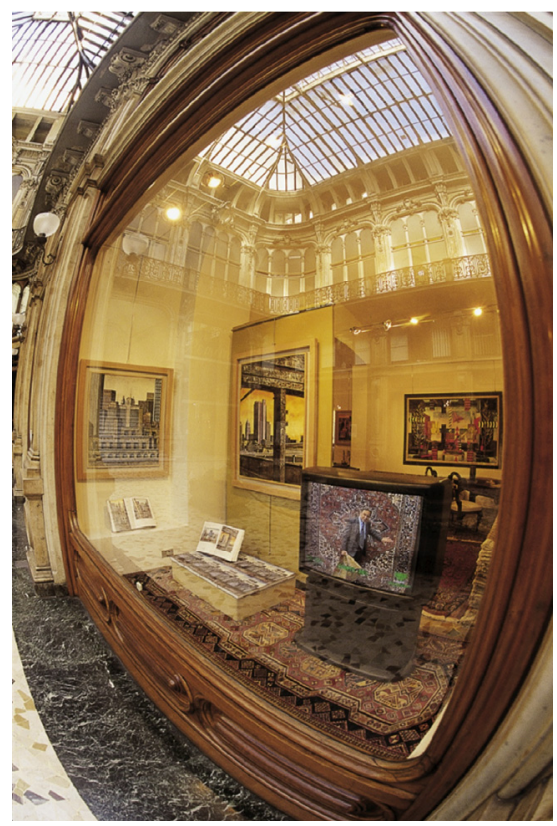

Figure 19: Turin, Italy.

WIT Transactions on the Built Environment, Vol 121, (C) 2011 WIT Press

www.witpress.com, ISSN 1743-3509 (on-line) 
At times one only has to change the frame very slightly to find very different lighting. For example, to include or exclude direct sunlight may lead to the creation of very different images, even though they are taken in the same place at the same time (Figs. 20(a), (b)-21(a), (b)).

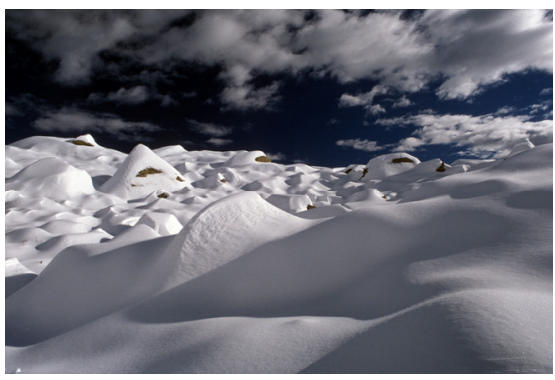

(a)

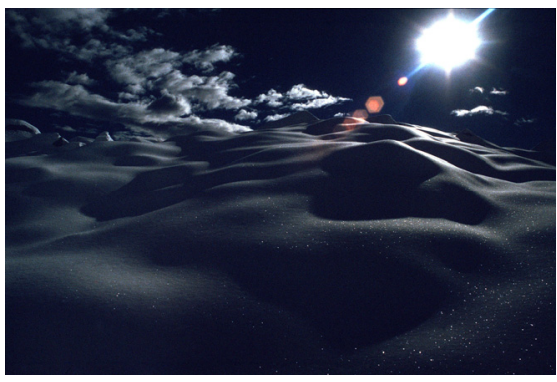

(b)

Figure 20: $\quad$ Oropa mountains, Italy.

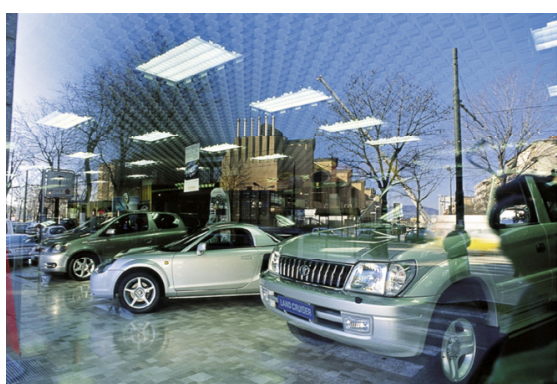

(a)

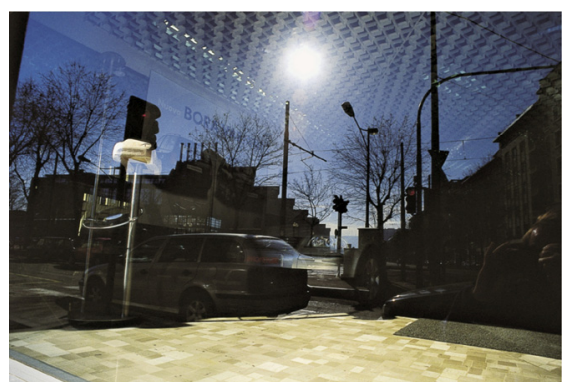

(b)

Figure 21: Turin, Italy.

It may be very important to observe a scene and wait for the right moment to take the photograph. In figure 22, for example, it was crucial to wait for a car lit up by the sun to give the picture an extra plane.

The photograph in figure 23 provides another example. The curtains inside the shop are gradually transformed into the buildings reflected and a face printed on a poster stuck on the shop-window appears. At the time the photo was taken the sun was appearing and disappearing behind the clouds and the photographer had to wait for it to light up the scene to give life and meaning to the whole image.

At other times, light models the subject for a fleeting moment: to catch it gives meaning to an otherwise commonplace image. The profile of the horse [3] is outlined by a very fine thread of light (Fig. 24). 


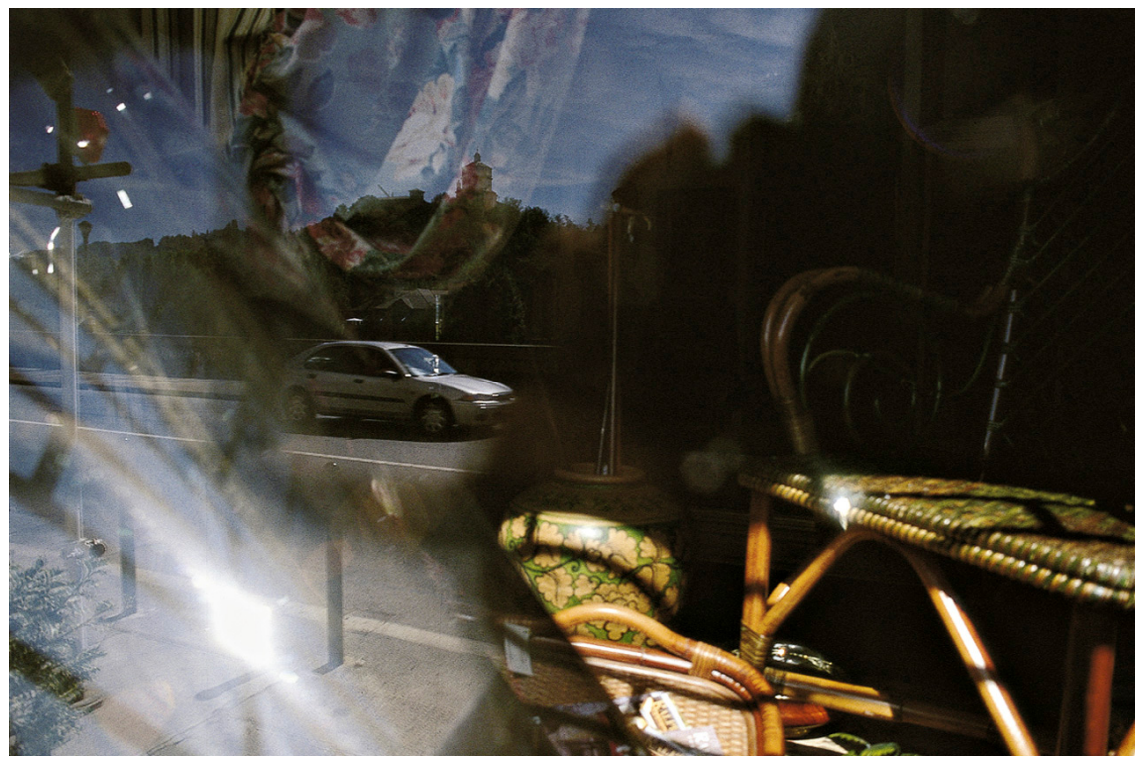

Figure 22: Turin, Italy.

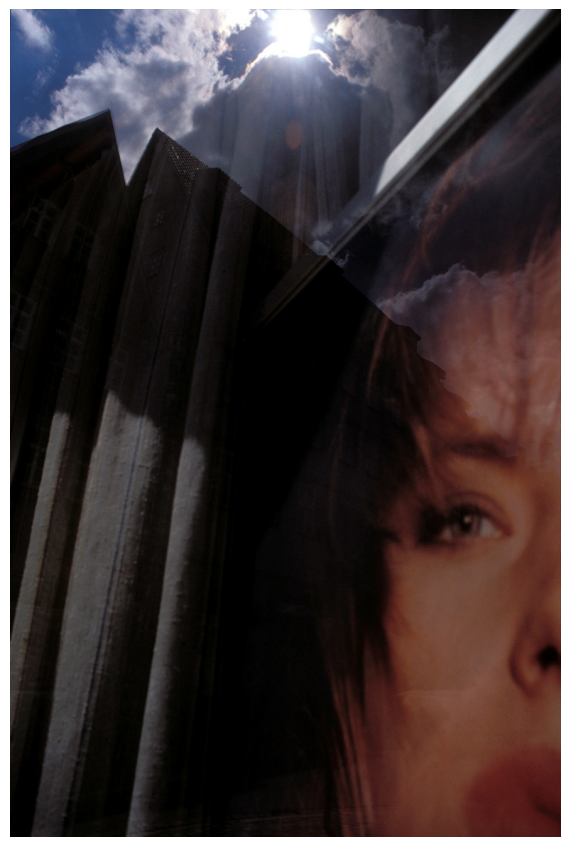

Figure 23: Coburg, Germany.

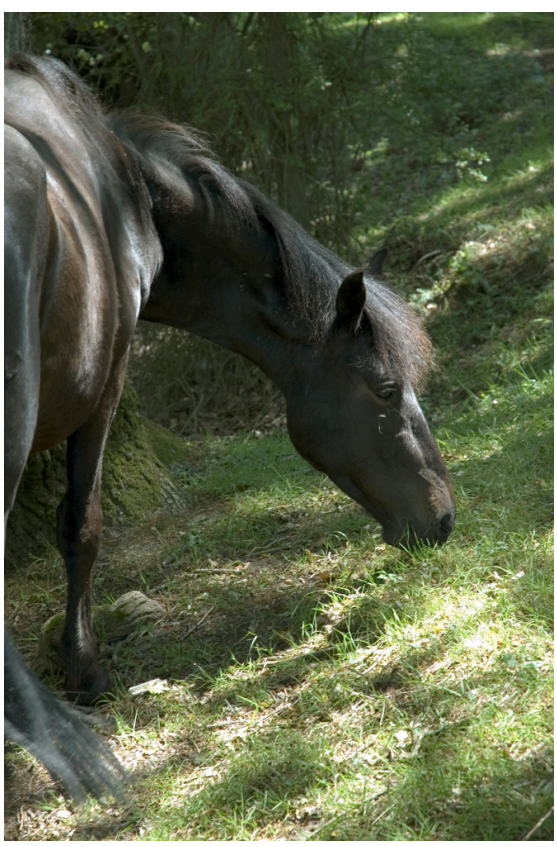

Figure 24: The New Forest, UK. 


\section{Conclusion}

If he is able to capture light the photographer can fix on paper images meaningful in content and aesthetic value which can acquaint us with reality very far from what we are accustomed to seeing. Thus photography becomes a figurative art, an instrument for the communication of beauty and knowledge.

In all its forms of expression art is always a means of communication, and hence involves not only those who create the work of art, but those who observe it as well. In the case of photography, it can be said that anyone looking at an artistic image will be able to take part in the creative process entailed in all forms of art.

Because of the character and the nature of the artistic images, those who look at them can do so through whatever "interpretation" they wish to give them, and will be able to grasp aspects and situations that are present in them but that the photographer himself may have not noticed while he was taking the pictures.

We can draw a useful comparison with Music: a composer writes a piece of music following his bent and developing some idea, but then, once it is on paper, that same piece of music can be interpreted in countless ways by different performers in later historical periods. Some of these interpretations the composer had never thought and could have not thought of, but were nonetheless present, hidden in the sheet of music he had written, were potentially there, right from the start. J.S. Bach could hardly have imagined, for instance, all the improvisations famous jazz players would perform centuries later on the basis of his compositions. In the same way photographs can be interpreted in many different ways, because they do not aim at being as-accurate-as-possible copies of what we all normally and absent-mindedly consider "reality", but rather at grasping and representing the "fantastic" yet true aspects of reality, which we much too often fail to see. Capturing the light is the way to do that.

\section{References}

[1] Pignone G.A., Strona P.P., Pieve di Teco e le sue "ville”, Editrice Morra, Almese (To), 2000, p. 236

[2] Strona P.P., Torino surreale, Editrice Morra, Almese (To), 2002

[3] Brebbia C.A., The New Forest, WIT Press, Southampton \& Boston, 2008

Note: This paper is available in a digital version, which includes images in their original colour format, from the WIT eLibrary (http://library.witpress.com) 